\title{
BioMedical Engineering OnLine: An Editorial
} Alvin Wald*

\author{
Address: Department of Biomedical Engineering Columbia University New York, NY USA \\ Email: Alvin Wald* - aw7@columbia.edu \\ * Corresponding author
}

Published: 02 June 2004

BioMedical Engineering OnLine 2004, 3:16
Received: 19 May 2004

Accepted: 02 June 2004

This article is available from: http://www.biomedical-engineering-online.com/content/3/1/16

(C) 2004 Wald; licensee BioMed Central Ltd. This is an Open Access article: verbatim copying and redistribution of this article are permitted in all media for any purpose, provided this notice is preserved along with the article's original URL.

\section{Greetings}

This month marks the two-year anniversary of the founding of "Biomedical Engineering OnLine." As it is customary to mark such occasions one way or another, and since I am the editor, I am contributing an editorial. I sometimes think that there is a human gene that is activated on anniversaries and so helps us to remember significant events. Putting it in writing insures the memory lasts a little longer. But the world has changed enormously since our genome was put together by that Great Biomedical Engineer in the sky. So I will try to make this editorial consistent with our new era of world-wide interconnectivity.

\section{Questions without answers}

The first issue to consider is why? Why another BME publication? Why an all electronic publication? Why me? The answers I can present will never tell the complete story, but like any good research, can only illuminate a small aspect of reality. Biomedical engineering is growing, and this growth is demonstrated by numerous new publications - each devoted to some recently exploited area of interest - or as the provenance of some new specialized organization based on geographical or technical convergence. While the growth of biomedical engineering is admirable, its fragmentation is not. More and more biomedical engineers become isolated. Publications cost money, in order to obtain print publications, libraries or individuals must either buy a subscription, or join yet another dues collecting organization. Costs have become prohibitive: just ask your library. A large number of biomedical engineers throughout the world thus simply lack access to vast quantities of relevant literature. But development of the world-wide-web has now provided a means to overcome this obstacle of costs. The Internet is providing a means for rapid and low-cost dissemination of technical information. It is the perfect medium by which researchers, rich and poor alike, can share the results of their works. There are no longer any limitations brought about by the high costs in time and money of print and paper production and transportation.

\section{My viewpoint}

Let us look at some of the specific changes in publishing between what was then and what is now. In a previous life, I was the editor of a print publication for many years. It was a rewarding experience at the time, but now with electronic publication the world has once again been rocketed into a new orbit, and a different set of parameters has evolved. Although editors and publishers may have to make some adjustments to this new order, authors will benefit significantly.

Consider the costs of traditional publication. Because of expenses associated with physical printing and distribution, authors were often limited in the number of pages allowed per article. Although this restraint might actually have benefited some papers (that is the editor in me speaking), it often put an additional burden on authors.

Furthermore, any use of colour in illustrations was strongly discouraged because of a significant cost increment (those infamous four-color separations). With electronic publishing, these limitations are no longer in effect. In fact, one can even insert moving graphics into an electronic publication, without arousing any cries of pain from the publisher. Even the tradition of ordering reprints and mailing autographed copies to friends and colleagues has essentially been ended, again a savings to the authors (as well as to filing space). In a few more years, how many of us will remember those euphoniously relics called 
"reprint request cards?" These being a victim of the selfreplicating copy machines. Another frustration for authors was the wait of many months, often over a year after acceptance, to see their articles in print. Here to, the limitation was often costs, i. e., a page limitation per issue by the publisher, as well as the ever blameworthy snail mail. Thus, with all electronic publishing, authors benefit in terms of both speed and completeness, as well as worldwide unlimited accessibility of their works.

But then, how did I get into this business of electronic publication. As I tell my students, I was a biomedical engineer before there was anything called biomedical engineering. It is very satisfying to me personally to see that they are completely disinterested in my revelation. Students have not changed over these many years. They want to know about the future, not the past, and that is good (up to a point. But that is a different editorial). Throughout the years I have had many friends and collaborators throughout the world. The more people I have met, the more I have seen the similarities in goals and outlooks. I believe that biomedical engineers are drawn into the discipline by a sense of wanting to control nature for the benefit of humanity. They see their research as a means of helping to solve some of the many problems that have troubled the world from pre-historic times and through the millenniums. Of course, both research and altruism are often lonely courses. Publication, especially with the rapid help of the Internet is one way to find like-minded, in goals and accomplishments, people around the globe.

So what is this electronic publishing all about? Simply stated, it is an entirely new paradigm in scientific communication. One way or another, we will all be affected by this new development in mass yet selective communication. I see my function as building connections among biomedical engineers, wherever they might be: to help them show their works to their colleagues. Often, researchers in less developed countries do not have the resources to be able to conduct research at the same level as in more fortunate societies. Yet the research results that they do produce may have significant bearing on reducing this disparity of resources. Moreover, the free on-line access to recent articles puts all researchers on an equal basis in knowing what areas are currently being investigated and what progress is being made.

I can observe a certain outlook in my relations with researchers at all level and over decades of age range. People seeking access to research papers can be divided into two major categories: those who say that if the work can not be found in print, it does not exist; and those who say that if the work cannot be found on-line, it does not exist. While age and computer facility seem to be the factors that delineate the two groups, more and more the latter group seems to predominate.

\section{Past, present, and future of "BioMedical Engineering OnLine"}

In my own personal experience, staring "BioMedical Engineering OnLine" has been a real kick. Only rarely in a lifetime can anyone say that he has started something from nothing, and helped it grow into a substantial entity. In its two years of publication, "BioMedical Engineering OnLine" has received some 55 manuscripts submitted and approximately 35 published. While I do take much pride in this accomplishment, I most certainly recognize and appreciate the many other biomedical engineers who have made enormous contributions. First of all, vision of the Biomed Central staff has made this all possible. They too have grown in accomplishment and service over the last two years, and I am sure that their success will only accelerate as Open Access Publication is recognized and accepted world-wide. The Editorial Board has been enormously supportive in both encouragement and actual work.

They have given full measure in carrying this publication forward. In particular, the Deputy Editor, Professor Ivan Daskalov of the Bulgarian Academy of Sciences, has been my stalwart friend and colleague in this endeavour. And of course, the many reviewers who have unselfishly provided their expert knowledge, all have my everlasting gratitude. It is the reviewers who bring the published articles to world-class standards of scientific research. Finally, no matter what we have done, it is the authors who deserve our maximum gratitude. Without these contributors, there would just not be anything to say. Their contributions are truly made "Biomedical Engineering OnLine" possible. They believe, as do so many of us, that free and unfettered access to scientific research is to the benefit of all humanity.

To paraphrase "The Bard of Avon:" anyone can predict the future, but will it come to be? The past two years have seen the genesis of a new publication in a new medium. It has been a success thanks to the unselfish efforts of many biomedical engineers throughout the world. My goal (if not prediction) for the future is to have "Biomedical Engineering OnLine" become even more important to its readers. I ask all readers to just let me know any of their suggestions to improve this publication. For it belongs to us all. 